\title{
Hibridização do ensino nos cursos de graduação presenciais das universidades federais: uma análise da regulamentação
}

\section{Blended learning on in-person undergraduate programs in federal universities:} an analysis on the regulation

Hibridación de la enseñanza en los cursos de graduación presenciales de las universidades federales: un análisis de la reglamentación

MICHELE REJANE COURA DA SILVA CRISTIANO MACIEL KÁTIA MOROSOV ALONSO

Resumo: A integração entre o ensino presencial e o virtual, o ensino híbrido, vem sendo foco de estudos no cenário mundial. No Brasil, a normatização da semipresencialidade, pela portaria $n^{\circ} 4.059 / 2004$, permitiu a hibridização do ensino. O objetivo deste estudo é analisar como as universidades federais estão ofertando o ensino híbrido em cursos de graduação presenciais, considerando-se sua regulamentação. $\mathrm{O}$ estudo teve abordagem qualitativa com viés exploratório descritivo, no qual foi realizada uma análise documental das regulamentações que autorizam a oferta do ensino híbrido nas universidades federais, bem como um questionário diagnóstico. A análise dos dados indica uma incompreensão acentuada do uso das tecnologias da informação e comunicação e de como elas podem ser apropriadas pelos cursos de graduação presenciais para fomentar a hibridização do ensino.

Palavras-chave: Portaria n. ${ }^{\circ}$ 4.059/2004. Semipresencialidade. Blended Learning. Ensino híbrido. Hibridização do ensino.

\begin{abstract}
The integration between in-person and virtual learning - hybrid learning - has been the focus of many studies around the world. In Brazil, Administrative Measure 4.059/2004 regulated the blended learning and allowed hybrid education. This study aims at analyzing how federal universities have been offering blended learning on in-person undergraduate programs considering its regulation. This research is a qualitative, descriptive and exploratory one, where, by the means of a diagnosis survey, we carried on a documental analysis of regulations that allow blended learning in Brazilian federal universities. Data analysis suggests there is a big misunderstanding concerning the use of information and communication technologies and how they can be used on in-person undergraduate programs to foster blended learning.
\end{abstract}

Keywords: Administrative measure 4.059/2004; blended learning; hybrid education.

Resumen: La integración de la enseñanza presencial y virtual: la enseñanza híbrida, está siendo el blanco de los estudios en el escenario mundial. En Brasil, la reglamentación dela semipresencialidad, por la resolución $\mathrm{n}^{\circ} 4.059 / 2004$, 
permitió la hibridación de la enseñanza. El objetivo del estudio fue analizar como las universidades federales ofrecen la enseñanza híbrida en cursos de graduación presenciales, considerando su reglamentación. El estudio tuvo un enfoque cualitativo con sesgo exploratorio descriptivo, en que fue realizado un análisis documental de los reglamentos que autorizan la oferta de la enseñanza híbrida enlas universidades federales, así como un cuestionario diagnóstico. El análisis de los dados indica una incomprensión acentuada en el uso de las tecnologías de la información y la comunicación y de cómo ellas pueden ser apropiadas por los cursos de graduación presenciales para fomentar la hibridación de la enseñanza.

Palabras clave: Resolución n. ${ }^{\circ}$ 4.059/2004; semipresencialidad; blended learning; enseñanza híbrida; hibridación de la enseñanza.

\section{INTRODUÇÃO}

A integração entre o ensino presencial e o virtual vem sendo foco de estudo no cenário mundial, como demonstra Belloni (2012) ao enfatizar que "as tendências mais fortes indicam para o desenvolvimento de modelos institucionais 'mistos' ou 'integrados' por meio dos quais as instituições convencionais de ensino superior ampliarão seus efetivos e diversificarão suas ofertas" (p. 117). Nesse sentido, Horn e Staker (2015), corroboram Belloni (2012), ao afirmarem que o blended learning, mescla do ensino presencial com o ensino virtual dentro e fora da escola, já se consolidou como uma das tendências mais importantes da educação do século XXI.

Essas práticas de blended learning (b-learning) ou ensino híbrido no Brasil também são denominadas como ensino semipresencial, bimodal ou misto. Sendo assim, as análises apresentadas nesta pesquisa consideram tais denominações como uma mesma modalidade ${ }^{1}$ de ensino.

As instituições de Ensino Superior (IES) estão modificando seus planejamentos pedagógicos por meio da implantação de modelos semipresenciais de educação a fim de modernizar o processo de ensino e aprendizagem. Essa implantação da semipresencialidade ocorre paralelamente à institucionalização da Educação a Distância (EaD). Os principais marcos da institucionalização da EaD são a Lei de Diretrizes e Bases da Educação Nacional (LDBEN) n ${ }^{\circ}$ 9.394/96 de 20 de dezembro de 1996, o Decreto nº $5.622^{2}$, de 20 de dezembro de 2005 e a

\footnotetext{
$1 \quad$ Neste estudo, em alguns momentos, o ensino semipresencial será tratado como modalidade de ensino por estar pautado no texto da Portaria MEC no 4.059, de 10/12/2004.

2 Esse decreto regulamentou a EaD como modalidade educacional em que a mediação didático-pedagógica nos processos de ensino e aprendizagem ocorre com a utilização de meios e tecnologias de informação e comunicação (PRETI, 2009).
} 
criação do sistema Universidade Aberta do Brasil $\left(\mathrm{UAB}^{3}\right)$ por meio do Decreto n. ${ }^{\circ} 5.800$ de 08 de junho de 2006, que proporcionaram um crescimento da modalidade de educação a distância nas instituições públicas de Ensino Superior (IPES) no país.

Até o ano de 2001, a legislação referente à EaD não normatizava o uso de atividades híbridas nos cursos presenciais das IES. As atividades foram regulamentadas por meio da portaria do Ministério da Educação (MEC) n $n^{\circ} 2.253$ de 18 de outubro de 2001. Em 2004, a publicação da Portaria MEC n 4.059, de 10 de dezembro de 2004, revogou a portaria no 2.253/2001, autorizando as IES a incluírem, na organização pedagógica e curricular de cursos em nível superior reconhecidos, até $20 \%$ da carga horária total do curso, o ensino semipresencial. Deve-se ressaltar que o Decreto n. ${ }^{o}$ 5.622/2005 não permite cursos totalmente a distância, exigindo momentos presenciais; sendo assim, mesmo cursos ofertados na modalidade EaD são semipresenciais.

A semipresencialidade permite que os cursos e, até mesmo, as disciplinas, possam ser planejadas tanto na forma presencial quanto on-line. Essa convergência entre presencial e virtual, chamada de ensino semipresencial, é um híbrido entre as duas modalidades e tem proporcionado às IES tanto vantagens - no sentido de aumentar os recursos e tecnologias empregadas no ensino - como desvantagens que podem ser visualizadas desde a infraestrutura necessária até o preparo para os profissionais da educação. Apresentam-se, segundo Moran (2015), inúmeras possibilidades de aprendizagem que combinarão o melhor do presencial com as facilidades do virtual.

Após onze anos da aprovação e publicação da Portaria n 4.059/2004, pouco se sabe a respeito dessa oferta de ensino. Portanto, o estudo pretende apresentar informações atualizadas sobre a semipresencialidade nas universidades federais (UF), procurando fazer um esclarecimento sobre hibridização do ensino nos cursos de graduação presenciais nessas instituições, que foram definidas como sujeitos da pesquisa por serem as únicas e restritas Instituições Federais de Ensino Superior (IFES) mencionadas e definidas na LDBEN n. ${ }^{\circ}$ 9.394/96.

Baseando-se no foco do estudo e valendo-se do viés exploratório descritivo da pesquisa, fez-se o levantamento hipotético, que afirma ter a ausência de um detalhamento da oferta de ensino híbrido por meio da portaria n. ${ }^{\circ} 4.059 / 2004$ ocasionado diferentes interpretações, dificultando sua implantação. Com base no exposto, o objetivo do estudo é analisar, considerando-se sua regulamentação,

3 O Sistema UAB foi instituído pelo decreto n. ${ }^{\circ}$ 5.800, de 08/06/2006, para o desenvolvimento da modalidade de educação a distância, com a finalidade de expandir e interiorizar a oferta de cursos e programas de Educação Superior no País. Disponível em http://www.uab.capes.gov.br/index.php/sobre-a-uab/o-que-e. Acessado em 14/10/2015. 
como as universidades federais estão ofertando o ensino híbrido em cursos de graduação presenciais.

Com relação aos caminhos utilizados para alcançar o objetivo da pesquisa, foi empregada a abordagem metodológica qualitativa (CHIZZOTTI, 2008; MARTINS, 2004). Utilizou-se a análise documental (LÜDKE; ANDRÉ, 1986; OLIVEIRA, 2007; GIL, 2010 e outros) para realizar o levantamento dos regulamentos pertencentes ao processo de institucionalização nas universidades federais que garantem a oferta e implantação do b-learning. Os dados também foram levantados por meio da aplicação de um questionário enviado às UF. Portanto, análise documental e questionário diagnóstico, analisados com viés exploratório descritivo, formam o corpus da pesquisa.

Além de uma revisão bibliográfica, foi desenvolvida uma revisão sistemática da literatura para demonstrar o cenário em que o ensino híbrido está inserido, apresentando-se informações referentes à institucionalização dessa modalidade, tendo como base um mapeamento das pesquisas já realizadas sobre $\mathrm{o}$ assunto.

\section{A HIBRIDIZAÇÃO DO ENSINO NO BRASIL}

A tendência que combina atividades desenvolvidas para o ensino e aprendizagem on-line com atividades desenvolvidas para o ensino e aprendizagem presencial, normalmente face a face, vem sendo referenciada na literatura por meio de diversas denominações, destacando-se o termo blended learning, cuja tradução mais aceita para o português é ensino híbrido (TORI, 2009).

Blended Learning (blended, do inglês "misturado") é a combinação de momentos em que o aluno estuda sozinho, virtualmente, com outros em que a aprendizagem ocorre de forma presencial, valorizando a interação entre alunos e professores. O objetivo do aprendizado híbrido é que esses dois momentos sejam complementares e promovam uma educação mais eficiente, interessante e personalizada (PORVIR, 2013).

Tori (2009), discorrendo sobre a convergência presencial e virtual, explica que "dois ambientes de aprendizagem que historicamente se desenvolveram de maneira separada, a tradicional sala de aula presencial e o moderno ambiente virtual de aprendizagem, vêm se descobrindo mutuamente complementares" (p.121). Como resultado dessa complementação têm-se os cursos híbridos, que procuram aproveitar o que há de vantajoso em cada modalidade, "considerando contexto, custo, adequação pedagógica, objetivos educacionais e perfis dos alunos" (Ibidem). 
Horn e Staker (2015) afirmam que “o ensino híbrido é o motor que pode tornar possível a aprendizagem centrada no estudante para alunos do mundo todo, em vez de apenas alguns privilegiados" (p. 54), corroborando, assim, a ideia de personalização da educação de Rumble (2000). Dessa forma, entende-se que uma importante característica do ensino híbrido é o fácil acesso às informações, em que o aluno aprende dentro de seu próprio ritmo e pode buscar conhecimento de acordo com suas próprias necessidades.

Percebe-se que, com essa abordagem (b-learning), os educadores podem, conforme Tori (2009), lançar mão de uma gama maior de recursos de aprendizagem, planejando atividades virtuais ou presenciais, "levando em consideração limitações e potenciais que cada uma apresenta em determinadas situações e em função da forma, conteúdo, custos e resultados pedagógicos desejados” (p. 121).

O fácil acesso a informações, possível pela integração das tecnologias da informação e comunicação (TIC) com a educação, permite que essa mescla entre sala de aula e ambientes virtuais abra as instituições para o mundo e também traga o mundo para dentro das instituições de ensino.

O ensino híbrido, segundo Moran (2015), integra as atividades da sala de aula com as digitais, as presenciais com as virtuais. $\mathrm{O}$ autor argumenta: "o que a tecnologia traz hoje é a integração de todos os espaços e tempos”. Sendo assim, "o ensinar e o aprender acontecem em uma interligação simbiótica, profunda e constante entre os chamados mundo físico e digital” (p. 39).

Para regulamentar essa oferta de ensino nas instituições de ensino superior brasileiras, a portaria n. ${ }^{\circ}$ 4.059, de 10 de dezembro de 2004 (regulamentação vigente), estabelece o seguinte:

As instituições de ensino superior poderão introduzir, na organização pedagógica e
curricular de seus cursos superiores reconhecidos, a oferta de disciplinas integrantes
do currículo que utilizem modalidade semi-presencial, com base no art. 81 da Lei
n. 9.394 , de 1.996 , e no disposto nesta Portaria. [...] $\ 1$ - Para fins desta Portaria,
caracteriza-se a modalidade semi-presencial como quaisquer atividades didáticas,
módulos ou unidades de ensino-aprendizagem centrados na auto-aprendizagem
e com a mediação de recursos didáticos organizados em diferentes suportes de
informação que utilizem tecnologias de comunicação remota. [...] $\ 2$ - Poderão
ser ofertadas as disciplinas referidas no caput, integral ou parcialmente, desde que
esta oferta não ultrapasse $20 \%$ (vinte por cento) da carga horária total do curso
(BRASIL, 2004, art. $1^{\circ}$ ).

A situação em que ocorre a educação semipresencial pode ser identificada quando o processo de ensino e aprendizagem acontece no ambiente presencial de sala de aula e sua complementação é trabalhada, a distância, por meio de diferentes tecnologias da informação e comunicação. 
O pouco tempo de aplicação das práticas virtuais juntamente com a modalidade presencial provoca muitas dúvidas entre os atores do processo de ensino aprendizagem, além de gerar modificações no sistema de gestão utilizado pelas IES que ofertam ou que implantaram a modalidade semipresencial.

O desenvolvimento de uma revisão sistemática objetivou descobrir de que maneira as IES estão ofertando o ensino híbrido em seus cursos presenciais. Para tanto, buscaram-se informações relativas às bases legais e às dificuldades encontradas para a oferta do b-learning.

Foram definidos como bases de dados eletrônicas o Portal de Periódicos da Coordenação de Aperfeiçoamento de Pessoal de Nível Superior (CAPES ${ }^{4}$ ) e Google Acadêmico ${ }^{5}$. Como critérios de inclusão, qualificaram-se os estudos sobre o ensino semipresencial implantados em IES, apresentados em teses, dissertações e artigos no idioma português, publicados entre os anos de 2010 e 2015. Como critérios excludentes, consideraram-se estudos fora do período pesquisado, repetidos (duplicados), em que o curso não é de ensino de graduação ou estudos em que o curso é semipresencial, porém a modalidade não é o foco da análise.

A análise dos textos resultou em uma amostra de cinco artigos. Moreira e Monteiro (2010) com o estudo "O trabalho pedagógico em cenários presenciais e virtuais no ensino superior" e Monteiro e Moreira (2012) com o estudo "O blended learning no ensino superior: reflexões em torno de práticas", foram selecionados no Portal de Periódicos Capes. Quevedo (2011) autor do artigo "O ensino semipresencial do ponto de vista do aluno", Costa, et. al (2012) com o estudo "Hibridização do ensino superior: avaliação de uma iniciativa na disciplina Introdução à Administração (Universidade de Brasília)" e Zanotto, et. al (2014) com o artigo "Hibridização do ensino em uma IES: delineamento de ações pedagógicas para a adoção de $20 \%$ a distância em cursos de graduação presenciais", fazem parte da amostra de estudos selecionados no Google Acadêmico.

Quanto às dificuldades apresentadas nos artigos analisados, estão estas relacionadas principalmente à apropriação por parte dos alunos em disciplinas na modalidade semipresencial. Dos cinco artigos revisados, dois apresentaram como dificuldade o fato de os alunos não possuírem computador em casa, dois fizeram referência à falta de feedback dos professores, três consideraram as dificuldades com o manuseio do Ambiente Virtual de Aprendizagem (AVA), um destacou a quantidade de material didático utilizado e um a linguagem do material didático. Apenas um artigo não mencionou dificuldades, seja no âmbito da instituição, do professor ou do aluno. Quanto às bases legais que autorizam a hibridização do

\footnotetext{
4 Portal de Periódicos da Capes: http://www.periodicos.capes.gov.br/

5 Google Acadêmico: http://scholar.google.com.br/?hl=pt-BR
}

100 - RBPAE - v. 33, n. 1, p. 095 - 117, jan./abr. 2017 
ensino, verificou-se que, dos cinco artigos selecionados na pesquisa, apenas um mencionou a regulamentação que embasa e permite a oferta do blended learning, a portaria n. ${ }^{\circ} 4.059 / 2004$.

A revisão sistemática permitiu constatar que a incógnita referente à oferta do ensino híbrido ainda precisa ser estudada para descobrir como b-learning ocorre, na prática, em todos os níveis da instituição de ensino. A primeira deficiência percebida refere-se à falta de estudos que tratem particularmente do processo de implantação para a oferta do ensino híbrido. Por fim, deve-se considerar, frente a essa análise, que há um longo caminho a se percorrer para tornar o ensino híbrido uma realidade permanente e efetiva nas IES brasileiras, tornando ainda mais relevante a iniciativa da dissertação de mestrado da qual este artigo apresenta um extrato dos resultados.

\section{REGULAMENTAÇÃO DO ENSINO HÍBRIDO NAS UNIVERSIDADES FEDERAIS: APRESENTAÇÃO E ANÁLISE DE DADOS}

As análises apresentadas no estudo foram desenvolvidas com base nas informações levantadas pela aplicação do questionário diagnóstico e pelas análises das regulamentações, no âmbito do Estado e da universidades federais que autorizam a oferta e implantação do b-learning nos cursos de graduação presenciais.

\section{SOBRE O QUESTIONÁRIO DIAGNÓSTICO}

Um questionário diagnóstico foi aplicado objetivando-se fazer um levantamento das UF que estão ofertando o ensino híbrido. Esse questionário foi encaminhado para as 63 universidades federais cadastradas no portal do Ministério da Educação.

Durante o período de encaminhamento e recepção, foram recebidas 17 respostas ao questionário. Assim, a amostra voluntária dessa etapa da pesquisa totalizou $27 \%$ de participação.

Das UF participantes na pesquisa, dez responderam estar ofertando a modalidade semipresencial. São elas: Universidade Federal da Fronteira Sul (UFFS), Universidade Federal dos Vales do Jequitinhonha e Mucuri (UFVJM), Universidade Federal do Piauí (UFPI), Universidade Federal da Grande Dourados (UFGD), Universidade Federal de Juiz de Fora (UFJF), Universidade Federal do Alagoas (UFAL), Universidade Federal do Cariri (UFCA), Universidade Federal de Lavras (UFLA), Universidade Federal de Mato Grosso (UFMT) e Universidade Federal de Uberlândia (UFU). No entanto, apesar de a UFU ter mencionado ofertar 
o ensino híbrido, verificou-se que ela possui regulamentação institucionalizada, porém não possui ainda cursos funcionando no formato híbrido.

Sete universidades federais participantes da pesquisa afirmam não ofertar o ensino híbrido, grupo em que se encontram a Universidade Federal do Ceará (UFC), Universidade Federal do Espírito Santo (UFES), Universidade Federal do Amazonas (UFAM), Universidade Federal do Acre (UFAC), Universidade Federal de São Carlos (UFSCar), Universidade Federal do Semi-Árido (UFERSA) e Universidade Federal do Rio Grande do Sul (UFRGS), sendo que esta última, apesar de não ter cursos nos moldes da semipresencialidade, já possui regulamentação que autoriza o ensino híbrido, não especificando, porém, a modalidade. Das UF que responderam ao questionário diagnóstico, foram analisados os regulamentos da UFU, UFSCar e da UFFS, que apresentaram regulamentação específica para o ensino semipresencial.

\section{SOBRE A ANÁLISE DOCUMENTAL: PORTARIA N. ${ }^{\circ} 2.253 / 2001$ E PORTARIA N. ${ }^{\circ} 4.059 / 2004$}

A fase inicial da análise documental foi desenvolvida com base na legislação do ensino híbrido. Como mencionado anteriormente, as práticas semipresenciais no Brasil foram autorizadas pela publicação da portaria $n^{\circ} 2.253 / 2001$, substituída posteriormente pela portaria $n^{\circ} 4.059 / 2004$.

A análise das portarias supracitadas evidenciou que elas estabelecem a importância da incorporação das TIC às práticas de ensino e aprendizagem híbridas e convergem quanto ao percentual de semipresencialidade, que deve ser de $20 \%$.

A análise das regulamentações específicas demonstrou que as UF têm observado esse percentual, mas discussões acerca dessa exigência já vêm sendo levantadas. Essa discussão a respeito dos 20\% de semipresencialidade foi colocada pelo Colégio de Pró-reitores de Graduação das IFES (COGRAD). O documento "Propostas do COGRAD para a Educação a Distância nas Instituições Federais de Ensino Superior ${ }^{6 "}$ " contesta esse percentual e ressalta a necessidade de revisão, considerando o avanço do uso das TIC na educação.

As principais modificações observadas entre as portarias referem-se à exigência de que as avaliações dos componentes curriculares híbridos sejam presenciais e à participação de tutoria, outro fator questionado pelo COGRAD. Salienta-se que tutores só serão necessários nos casos em que a disciplina semipresencial for ministrada totalmente a distância.

$6 \quad$ Disponível em $<$ http://www.andifes.org.br $>$.

102 - RBPAE - v. 33, n. 1, p. 095 - 117, jan./abr. 2017 


\section{SOBRE A ANÁLISE DA REGULAMENTAÇÃO DO ENSINO HÍBRIDO NAS UF}

A segunda fase da análise documental foi desenvolvida após busca por documentações nos sites/portais das 63 universidades federais ativas cadastradas no sistema e-MEC ${ }^{7}$ e considerando as respostas ao questionário diagnóstico aplicado. A sistematização da busca por documentações (resoluções, regulamentos, regimentos, atos decisórios, entre outros) estabeleceu descritores como critérios de busca, que foram: semipresencial e outras formas de sua escrita como semipresencial ou semi presencial, já que essas variações podem ser encontradas após publicação da Portaria n. ${ }^{\circ}$ 2.253/2001 devido às alterações nas normas dos acordos ortográficos autorizados pelo MEC; ensino híbrido (hibridismo ou hibridização); blended learning; 20\% a distância; ou ainda, portaria n. ${ }^{\circ}$ 4.059/2004.

A análise dos regulamentos foi baseada nos elementos dos Processos de Gestão em EaD descritos por Petter (2010), que são os processos pedagógicos, administrativos, financeiros e tecnológicos. Os elementos desses processos deram origem ao Quadro 1.

\section{Quadro 1: Elementos que compõem as Dimensões da análise documental.}

\begin{tabular}{|c|c|c|}
\hline & Dimensões & Elementos \\
\hline \multirow{7}{*}{1} & \multirow{7}{*}{ Dimensão pedagógica } & $\begin{array}{c}1 \text {-Elaboração e desenvolvimento do projeto político-pedagógico do } \\
\text { curso }\end{array}$ \\
\hline & & 2 - Elaboração do material didático \\
\hline & & 3 - Trabalho dos professores \\
\hline & & 4 - Formação dos tutores/orientadores acadêmicos \\
\hline & & 5 - Dinâmica do trabalho pedagógico \\
\hline & & 6 - Avaliação da aprendizagem e do material pedagógico \\
\hline & & 7 - Elaboração do plano de ensino da disciplina \\
\hline
\end{tabular}

$7 \quad$ O e-MEC foi criado para fazer a tramitação eletrônica dos processos de regulamentação. Pela internet, as instituições de Educação Superior fazem o credenciamento e o recredenciamento, buscam autorização, reconhecimento e renovação de reconhecimento de cursos. 


\section{Quadro 1: Elementos que compõem as Dimensões da análise documental.}

\begin{tabular}{|c|c|c|}
\hline & Dimensões & Elementos \\
\hline \multirow{7}{*}{2} & \multirow{7}{*}{$\begin{array}{l}\text { Dimensão administrativo- } \\
\text { financeira }\end{array}$} & 1 - Parcerias e convênios \\
\hline & & 2 - Recursos físicos e materiais \\
\hline & & 3 - Distribuição do material didático \\
\hline & & 4 - Seleção de recursos humanos \\
\hline & & 5- Registro acadêmico e documental \\
\hline & & 6 - Disseminação de informações \\
\hline & & 7 - Avaliação do trabalho de recursos humanos \\
\hline \multirow{3}{*}{3} & \multirow{3}{*}{ Dimensão tecnológica } & 1 - Garantia de infraestrutura tecnológica \\
\hline & & 2 - Criação de software e/ou sistemas \\
\hline & & Operação e manutenção dos meios tecnológico \\
\hline
\end{tabular}

Fonte: Petter (2010).

No início, procurava-se apresentar apenas os elementos das dimensões investigadas nas regulamentações das UF; porém, por meio da análise desses documentos, percebeu-se que o apontamento de outros elementos seria necessário para subsidiar o alcance de respostas que permitissem a análise de como as UF estão ofertando o ensino híbrido em seus cursos de graduação presenciais, considerando a portaria n. ${ }^{\circ}$ 4.059/2004. Em consequência dessa constatação, a construção do Quadro 2 demonstra os elementos: autorização da oferta de ensino; definição do ensino híbrido; presença de descrição dos elementos das dimensões analisadas ou replicação da portaria n. ${ }^{\circ}$ 4.059/2004.

\section{Quadro 2: Amostra de UF que possuem regulamentação específica para o ensino semipresencial.}

\begin{tabular}{|c|c|c|}
\hline Universidade Federal / Sigla & Regulamento & Características \\
\hline $\begin{array}{c}\text { Fundação Universidade Federal do } \\
\text { ABC / UFABC }\end{array}$ & $\begin{array}{c}\text { Ato Decisório n. }{ }^{\circ} 74 \text { de 6/11/2012. } \\
\text { Conselho de Ensino, Pesquisa e } \\
\text { Extensão. }\end{array}$ & $\begin{array}{c}\text { - Apenas autoriza a oferta } \\
\text { de ensino. Não traz qualquer } \\
\text { informação adicional sobre os } \\
\text { elementos que compõem as } \\
\text { Dimensões analisadas. } \\
\text {-Não conceitua "ensino híbrido". }\end{array}$ \\
\hline $\begin{array}{c}\text { Universidade Federal do Mato Grosso do } \\
\text { Sul / UFMS }\end{array}$ & $\begin{array}{c}\text { - Autoriza a oferta do ensino híbrido. } \\
\text { - Conceitua "ensino híbrido" } \\
\text { como constituído de atividades } \\
\text { presenciais e a distância. } \\
\text { - Replica, em maior parte, as } \\
\text { Conselho de Ensino de Graduação. } \\
\text { informações da Portaria 4.059/2004. } \\
\text { - Elemento Pedagógico: exige } \\
\text { capacitação e credenciamento para } \\
\text { o docente. }\end{array}$ \\
\hline
\end{tabular}




\section{Quadro 2: Amostra de UF que possuem regulamentação específica para o}

ensino semipresencial.

\begin{tabular}{|c|c|c|}
\hline Universidade Federal / Sigla & Regulamento & Características \\
\hline $\begin{array}{c}\text { Universidade Federal do Paraná } \\
\text { / UFPR }\end{array}$ & $\begin{array}{c}\text { Resolução n. }{ }^{0} 72 \text { de 22/10/2010. } \\
\text { Conselho de Ensino, Pesquisa e } \\
\text { Extensão. }\end{array}$ & $\begin{array}{c}\text { - Regulamenta a oferta de } \\
\text { disciplinas na modalidade a } \\
\text { distância nos cursos de graduação } \\
\text { presenciais. } \\
\text { - Conceitua o blended learning } \\
\text { como oferta de disciplina integral ou } \\
\text { parcialmente a distância (não usa o } \\
\text { termo semipresencial). } \\
\text { - Elementos Tecnológicos: a } \\
\text { UFPR se responsabiliza pela } \\
\text { disponibilização de serviços de } \\
\text { tecnologia e comunicação. } \\
\text { - Elementos Pedagógicos: o tutor é } \\
\text { o professor que ministra a disciplina } \\
\text { híbrida. O professor/tutor deverá } \\
\text { ser capacitado para atuar em } \\
\text { programas EaD. }\end{array}$ \\
\hline $\begin{array}{c}\text { Universidade Federal da Fronteira Sul } \\
\text { / UFFS }\end{array}$ & $\begin{array}{l}\text { Resolução n. }{ }^{\circ} 5 \text { de 26/06/2014. Câmara } \\
\text { de Graduação do Conselho Universitário. }\end{array}$ & $\begin{array}{c}\text { - Autoriza a oferta de disciplinas } \\
\text { no formato híbrido nos cursos de } \\
\text { graduação presenciais. } \\
\text { - Conceitua a modalidade } \\
\text { semipresencial da mesma forma } \\
\text { que a portaria n. }{ }^{\circ} 4.059 / 2004 . \\
\text { - Elementos pedagógicos: } \\
\text { estabelece os componentes } \\
\text { do Projeto Político Pedagógico } \\
\text { do curso (PPC) que contém } \\
\text { componentes curriculares no } \\
\text { formato híbrido. Garante a formação } \\
\text { dos docentes para o uso de } \\
\text { tecnologias e Ambiente Virtual de } \\
\text { Aprendizagem (AVA). } \\
\text { - Elementos administrativos: } \\
\text { assegura condições para a } \\
\text { elaboração do material didático. } \\
\text { Traz informações sobre seleção } \\
\text { docente. }\end{array}$ \\
\hline
\end{tabular}




\section{Quadro 2: Amostra de UF que possuem regulamentação específica para o ensino semipresencial.}

\begin{tabular}{|c|c|c|}
\hline Universidade Federal / Sigla & Regulamento & Características \\
\hline $\begin{array}{l}\text { Universidade Federal de Uberlândia } \\
\qquad \text { / UFU }\end{array}$ & $\begin{array}{l}\text { Resolução n. }{ }^{0} 35 \text { de 18/11/2011. } \\
\text { Conselho de Graduação. }\end{array}$ & $\begin{array}{l}\text { - Regulamenta a oferta de componentes } \\
\text { curriculares híbridos nos cursos de } \\
\text { graduação presenciais. } \\
\text { - Estabelece o ensino semipresencial } \\
\text { como a incorporação de meios } \\
\text { e tecnologias de informação e } \\
\text { comunicação como mediação didático- } \\
\text { pedagógica nos processos de ensino e } \\
\text { aprendizagem. } \\
\text { - Elementos pedagógicos: estabelece } \\
\text { que as atividades de acompanhamento } \\
\text { pedagógico deverão ser desenvolvidas } \\
\text { pelos docentes da UFU que demonstrem } \\
\text { domínio da utilização das TIC e interesse } \\
\text { nelas, mas não traz informações sobre } \\
\text { capacitação docente. } \\
\text { - Elementos administrativos: assegura } \\
\text { condições para elaboração do material } \\
\text { didático. } \\
\text { - Elementos tecnológicos: exige a } \\
\text { indicação, por parte dos responsáveis } \\
\text { do curso/disciplina híbridos, do AVA a } \\
\text { ser utilizado e garante infraestrutura } \\
\text { tecnológica. }\end{array}$ \\
\hline $\begin{array}{l}\text { Universidade Federal do Estado do Rio } \\
\text { de Janeiro / UNIRIO }\end{array}$ & $\begin{array}{c}\text { Resolução n. }{ }^{\circ} 4.101 \text { de 30/04/2013. } \\
\text { Conselho de Ensino, Pesquisa e } \\
\text { Extensão. Deliberação do Conselho } \\
\text { de Estratégias Acadêmicas n. }{ }^{\circ} 04 \text { de } \\
\text { 14/12/2009. }\end{array}$ & $\begin{array}{l}\text { - Autoriza a oferta e funcionamento das } \\
\text { disciplinas híbridas. } \\
\text { - Conceitua equivocadamente o ensino } \\
\text { semipresencial através do Art. } 1^{\circ} \text { do } \\
\text { Decreto n. } .^{\circ} 5.622 \text { de } 19 / 12 / 2005 . \\
\text { - Elementos pedagógicos: traz } \\
\text { informações sobre as atividades de } \\
\text { tutoria. Define normas para as atividades } \\
\text { presenciais. Traz informações sobre } \\
\text { o Plano de Ensino dos componentes } \\
\text { curriculares na modalidade } \\
\text { semipresencial. }\end{array}$ \\
\hline $\begin{array}{l}\text { Universidade Federal de Santa Catarina } \\
\text { / UFSC }\end{array}$ & $\begin{array}{l}\text { Resolução n. }{ }^{\circ} 002 \text { de 02/03/2007. } \\
\text { Conselho Universitário. }\end{array}$ & $\begin{array}{c}\text { - Dispõe sobre o programa de EaD } \\
\text { da UFSC. - Autoriza a oferta do } \\
\text { semipresencial. } \\
\text { - Define o ensino hibrido conforme } \\
\text { portaria n. }{ }^{\circ} .059 / 2004 . \\
\text { - Elementos pedagógicos: estabelece } \\
\text { uma composição superficial do PPC } \\
\text { dos cursos semipresenciais. Garante } \\
\text { a participação de tutoria e capacitação } \\
\text { para atuar na modalidade de EaD. } \\
\text { - Elementos administrativo-financeiros: } \\
\text { Traz informações sobre a gestão } \\
\text { financeira dos cursos. } \\
\text { - Elementos tecnológicos: responsabiliza- } \\
\text { se pela estrutura tecnológica do curso. }\end{array}$ \\
\hline
\end{tabular}




\section{Quadro 2: Amostra de UF que possuem regulamentação específica para o ensino semipresencial.}

\begin{tabular}{|c|c|c|}
\hline Universidade Federal / Sigla & Regulamento & Características \\
\hline Universidade Federal de Viçosa / UFV & $\begin{array}{c}\text { Resolução n. } 02 \text { de 19/02/2008. } \\
\text { Conselho de Ensino, Pesquisa e } \\
\text { Extensão. }\end{array}$ & $\begin{array}{l}\text { - Autoriza a oferta de ensino dispondo } \\
\text { normas para a inclusão de disciplinas } \\
\text { semipresenciais em cursos superiores } \\
\text { presenciais. } \\
\text { - A semipresencialidade é caracterizada } \\
\text { como organização em módulos ou } \\
\text { unidades em que há integração das } \\
\text { novas tecnologias da informação e } \\
\text { comunicação não-presenciais. } \\
\text { - Elementos pedagógicos: estabelece } \\
\text { as formas em que a disciplina híbrida } \\
\text { deve ser ofertada. Faz o detalhamento } \\
\text { de como devem ser as avaliações de } \\
\text { aprendizagem e o número de encontros } \\
\text { presenciais. Trata da avaliação do } \\
\text { rendimento acadêmico, especificando } \\
\text { seus critérios. } \\
\text { - Elemento tecnológico: menciona o } \\
\text { AVA que deve ser utilizado nas práticas } \\
\text { semipresenciais, o PVANet. }\end{array}$ \\
\hline $\begin{array}{c}\text { Universidade Federal de São Carlos / } \\
\text { UFSCar }\end{array}$ & $\begin{array}{c}\text { Portaria GR n.0 } 1.502 \text { de 23/10/2012. } \\
\text { Conselho Universitário. }\end{array}$ & $\begin{array}{c}\text { - Dispõe sobre a política de EaD na } \\
\text { UFSCar. - Autoriza a oferta de disciplinas } \\
\text { na modalidade EaD em cursos de } \\
\text { graduação presenciais. } \\
\text { - Define o ensino hibrido conforme texto } \\
\text { da portaria n. }{ }^{\circ} 4.059 / 2004 \text {. } \\
\text { - Elementos pedagógicos: define os } \\
\text { componentes dos planos de ensino das } \\
\text { disciplinas semipresenciais. Estabelece } \\
\text { que as avaliações das atividades } \\
\text { semipresenciais devem corresponder a } \\
49 \% \text { da nota da disciplina. } \\
\text { - Elementos tecnológicos: indica o uso } \\
\text { de pelo menos três mídias diferentes } \\
\text { para o desenvolvimento do componente } \\
\text { curricular. Exige a responsabilidade } \\
\text { do professor quanto ao conteúdo das } \\
\text { mídias. Garante } 0 \text { apoio tecnológico } \\
\text { da equipe técnica da Secretaria Geral } \\
\text { da EaD. }\end{array}$ \\
\hline
\end{tabular}

Foram encontrados documentos regulamentadores do ensino híbrido em apenas nove das UF pesquisadas. Isso significa que 14,3\% das 63 universidades federais, possuem normatização específica para a oferta do ensino híbrido e já estão em processo de institucionalização dessa oferta. Apesar de ser considerada pequena a amostra, pondera-se que o ensino híbrido foi regulamentado no Brasil há apenas 11 anos.

Das nove UF que possuem regulamentação específica para o ensino semipresencial, oito apresentam informações sobre os elementos analisados na pesquisa. São elas: UFMS, UFPR, UFFS, UFU, UNIRIO, UFSC, UFV e UFSCar. 
A UF que não faz referência às dimensões analisadas é a UFABC, que autoriza b-learning por meio do Ato Decisório n. ${ }^{\circ}$ 74/2012, que aprova a mediação da educação por novas TIC na modalidade semipresencial.

Elementos pedagógicos foram apresentados pelas regulamentações de oito universidades federais. Seis dos sete elementos constitutivos dessa Dimensão foram verificados nas regulamentações. Apresentaram o elemento D1-1 e D1-2 a UFFS e a UFU; o elemento D1-3 foi observado na UFPR, UFFS, UFU, UFSC e UFMS. Universidade Federal de Santa Catarina. UNIRIO, UFU e UFPR apresentaram o elemento D1-4; o elemento D1-5, que aborda a dinâmica do trabalho pedagógico, não foi encontrado em regulamento algum e o elemento D1-6 foi visualizado no regulamento da UFSCar e da UNIRIO.

A Dimensão administrativo-financeira foi a menos encontrada no texto das regulamentações analisadas. O único elemento visualizado foi o D2-4, que se refere à seleção de recursos humanos. No entanto, as informações apresentadas nos regulamentos da UFPR, UFU e UFMS não demonstraram conteúdo suficiente para uma discussão aprofundada.

Por fim, a dimensão tecnológica, que também não foi muito abordada pelas regulamentações, apresentou o elemento D3-1 por parte do regulamento da UFSC, UFU e da UFPR e o elemento D3-2 pela UFU, UFV e UFSCar. O elemento não encontrado, D3-3, trata da operação e manutenção dos meios tecnológicos. Pelo exposto, somente cinco UF demonstraram preocupação em abordar o uso das TIC em suas normatizações. Essa constatação é totalmente discrepante do conteúdo da portaria n. ${ }^{\circ}$ 4.059/2004 que exige em seu Art. $2^{\circ}$ que as disciplinas híbridas incluam métodos e práticas de ensino e aprendizagem que incorporem o uso integrado de tecnologias da informação e comunicação.

A primeira constatação permitida por meio da análise dessas dimensões, é que elas não são suficientes para abranger a totalidade de informações necessárias para a efetiva implantação da blended learning. Destarte, o Quadro 2 traz, além dessas dimensões, informações referentes à autorização da oferta da semipresencialidade e a conceituação do ensino híbrido. Dessa forma, considerando-se o ensino híbrido, os processos de gestão deveriam ser alargados para abarcar todas as especificidades indispensáveis à hibridização do ensino. Assim, sugere-se a extensão dos elementos que compõem os processos de gestão propostos por Petter (2010).

O regulamento que apresentou maior número de informações referentes às dimensões estudadas na análise documental foi a Resolução n. ${ }^{\circ}$ 05/2014, da UFFS, que demonstrou um entendimento mais claro da implantação do ensino híbrido. 
Essa defasagem comprova a afirmação feita por esta pesquisa de que este estudo indica uma incompreensão acentuada no uso das tecnologias e de como elas devem ser apropriadas pelos cursos de graduação presenciais. Portanto, entende-se que há uma incompreensão em torno do ensino on-line e de sua relação com o ensino presencial.

Com base nos regulamentos analisados, tanto pelo Quadro 2 quanto pelo questionário diagnóstico, constatou-se que nove universidades federais estão ofertando o ensino híbrido, representando 14,3\% do total de UF pesquisadas.

Por meio da busca realizada nos sites/portais das UF, verificou-se que, apesar de não possuírem ou não disponibilizarem qualquer documento aprovado pela própria instituição que regulamente a oferta do ensino semipresencial, algumas UF mencionam a portaria n. ${ }^{\circ}$ 4.059/2004, sinalizando que essas universidades podem estar ofertando cursos/disciplinas híbridos.

\section{SOBRE OUTROS ELEMENTOS APONTADOS PELOS REGULAMENTOS QUE AUTORIZAM A HIBRIDIZAÇÃO DO ENSINO NAS UF}

Um dos elementos analisados refere-se à autorização da oferta do ensino híbrido. Todos os documentos analisados autorizam e regulamentam a oferta de cursos/disciplinas híbridas, com exceção do ato decisório n. ${ }^{\circ}$ 74/2012 da UFABC que apenas autoriza a oferta do b-learning. Deve-se enfatizar que essa autorização não é garantia da efetividade da utilização de práticas híbridas nos cursos de graduação presenciais.

Também foram encontradas informações sobre a definição do ensino híbrido nas regulamentações. A conceituação da semipresencialidade foi observada nas normatizações para verificar como as universidades federais estão entendendo essa prática de ensino. Observou-se uma falta de entendimento quanto às práticas de ensino híbridas, que pode estar gerando os equívocos encontrados nos documentos e, consequentemente, uma falta de informações que subsidiem a implantação da modalidade nos cursos de graduação presenciais das UF.

A Resolução n. ${ }^{\circ}$ 05/2014, da UFFS, Resolução nº 002/2007, da UFSC, a Portaria GR n. ${ }^{\circ}$ 1.502/2012, da UFSCar e a Resolução n. ${ }^{\circ}$ 02/2008, da UFV conceituam o ensino híbrido da mesma forma como o texto da portaria $n^{\circ}$ $4.059 / 2004$.

A conceituação de "ensino híbrido" encontrada na Resolução n. ${ }^{\circ}$ 4.101/2013, da UNIRIO, foi a mais discrepante de todos os documentos analisados e, até mesmo, da portaria n. ${ }^{\circ}$ 4.059/2004. Apresenta-se nessa resolução 
o equívoco constantemente encontrado nas regulamentações e publicações sobre o b-learning, ao se tratá-lo como combinação entre o ensino presencial e educação a distância, equívoco que também foi visualizado nos documentos da UFMS, UFPR e da UFPI. Mencionou-se na resposta ao questionário diagnóstico que " $A$ resolução apenas institucionaliza a oferta de até $20 \%$ da carga horária da disciplina podendo ser disponibilizada na modalidade EaD desde que contemplada no PPC."

O ensino híbrido é a convergência entre o ensino presencial e o virtual, conceituação apoiada por Moran (2004), Tori (2009), Porvir (2013) e Horn e Staker (2015). Acredita-se que o entendimento equivocado, do semipresencial como sendo a integração entre presencial e a distância, pode estar sendo influenciado pelo texto da portaria n. ${ }^{\circ} 4.059$, quando explica que explica:

\footnotetext{
Para os fins desta Portaria, entende-se que a tutoria das disciplinas ofertadas na modalidade semi-presencial implica na existência de docentes qualificados em nível compatível ao previsto no projeto pedagógico do curso, com carga horária específica para os momentos presenciais e os momentos a distância (BRASIL, 2004 , art. $2^{\circ}$, parágrafo único, grifo nosso).
}

A Portaria determina que "poderão ser ofertadas as disciplinas referidas no caput [do artigo], integral ou parcialmente, desde que esta oferta não ultrapasse $20 \%$ da carga horária total do curso" (Idem, art. $1^{\circ}$, parágrafo $2^{\circ}$. grifo nosso). Os componentes curriculares híbridos, segundo a Portaria, podem ser implantados de duas formas: a disciplina pode ser planejada considerando que até $20 \%$ de sua carga horária poderá ser ministrada por meio das TIC, e os 80\% restantes no formato presencial (caracterizando a semipresencialidade), ou o componente curricular pode ser ministrado totalmente a distância, garantindo os encontros presenciais, sendo que o número de disciplinas nesse formato não poderá exceder $20 \%$ da carga horária total do curso. Assim, o curso seria considerado semipresencial, com disciplinas presencias e disciplinas realizadas a distância. É este segundo caso que pode estar gerando a confusão no entendimento de como o ensino híbrido deve ser concebido.

O único regulamento que mencionou a forma como o componente curricular deverá ser ministrado foi a Resolução n. ${ }^{\circ}$ 4.101/2013, da UNIRIO, que deixou claro deverem as disciplinas híbridas ser ministradas totalmente a distância. Dessa forma, levando-se em consideração que esse regulamento menciona a exigência dos encontros presenciais, verifica-se, com base na análise de informações, que a taxonomia do ensino híbrido empregada nas disciplinas semipresenciais da UNIRIO é a do Modelo Virtual Enriquecido, aquele em que no curso ou na disciplina os estudantes têm sessões de aprendizagem presencial obrigatórias com seu professor e, então, ficam livres para completar o trabalho restante do curso distante do professor presencial (HORN; STAKER, 2015).

110 - RBPAE - v. 33, n. 1, p. 095 - 117, jan./abr. 2017 
Nos casos em que os regulamentos não esclarecem a forma como a disciplina híbrida deve ser ministrada, com base na análise deste estudo, a observância dos 20\% da carga horária sugere a utilização do Modelo de Rotação - Sala de Aula Invertida, estabelecido por Horn e Staker (2015), no qual em um curso ou disciplina os estudantes têm ensino online fora da sala de aula, em lugar de lição de casa tradicional. Ressalta-se que a falta de informações detalhadas sobre a forma como os componentes curriculares são ministrados dificulta uma análise aprofundada dos modelos híbridos empregados pelas UF que ofertam ou já regulamentaram a hibridização do ensino.

Essa falta de informações sobre o formato semipresencial denota a autonomia impressa pelos regulamentos do ensino híbrido, corroborando o apontamento de Moran, Araújo Filho e Sidericoudes (2005), que caracteriza esses casos como voluntarismo, em que a IES deixa livre a adesão dos professores ao uso de atividades que utilizem o formato híbrido.

Outra discussão a respeito dos $20 \%$ de semipresencialidade foi colocada, como citado anteriormente, pelo documento do COGRAD em seu extrato que aborda "Considerações sobre a EaD nas IES Públicas", enfatizando que:

A Portaria $n^{\circ} 4.059 / 2004$ necessita de revisão, principalmente, em relação ao percentual estabelecido de $20 \%$ para a $\mathrm{EaD}$, que já não tem mais sentido diante do avanço das TIC. Além disso, a tutoria virtual necessita ser revista, de modo a se configurar como atividade profissional, regulamentada e reconhecida pelas IES (COGRAD, 2015).

Com este enfoque Belloni (2012, p. 64) afirma que as TIC "oferecem possibilidades inéditas de interação mediatizada (professor/aluno; estudante/ estudante) e de interatividade com materiais de boa qualidade e de grande variedade". Sendo assim, para compreender o papel das TIC na educação é preciso considera-las como ferramentas pedagógicas, "deixando de lado, nessa análise, seus usos como meios de circulação de informação geral ou administrativa nos sistemas educacionais" (idem, p. 65).

A resposta ao questionário diagnóstico da Universidade Federal de Lavras foi que "O fato é que em nenhum caso essa oferta ultrapassa $20 \%$ da $\mathrm{CH}$ do curso pois as disciplinas semipresenciais não têm autorização para ofertar mais que $20 \%$ de sua $\mathrm{CH}$ a distância. Este é um dos problemas que resolveremos com a aprovação do regulamento no CEPE” (sic.) Isso já identifica que a UFLA considera a necessidade de repensar os $20 \%$.

Fica demonstrado, para além da hibridização do ensino, como esclarece Belloni (2012), que, embora as TIC não tenham demonstrado sua eficácia pedagógica, "elas estão cada vez mais presentes na vida cotidiana e fazem parte do 
universo dos jovens, sendo essa a razão principal da necessidade de sua integração à educação" (p. 82, grifo da autora). Portanto, percebe-se que uma possível incompreensão de como integrar as TIC à educação pode estar refletindo-se em uma implantação equivocada da semipresencialidade.

Conforme dados levantados pela pesquisa, regulamentaram a oferta do ensino híbrido nove universidades federais: a UFABC, UFMS, UFPR, UFFS, UFU, UNIRIO, UFSC, UFV e UFSCar, totalizando 14,3\%. Essa indicação do percentual de UF que regulamentam o b-learning não considera a insuficiência de informações que essas normatizações demonstram. Apesar de não fomentar uma adequada oferta da semipresencialidade, essas regulamentações sinalizam um movimento institucional que procura viabilizar o hibridismo.

\section{CONSIDERAÇÕES FINAIS}

Torna-se importante considerar que a falta de informações abrangentes observadas na portaria n. ${ }^{\circ}$ 4.059/2004 indica uma autonomia disfarçada, já que a Portaria não dá subsídios para uma adequada implantação do hibridismo e sugere uma insuficiência de concepção que tem gerado equívocos em sua interpretação e aplicação e, consequentemente, na elaboração de regulamentações por parte das universidades federais. No entanto, os resultados desta pesquisa apontam que o processo de implantação e oferta do ensino híbrido vem ocorrendo paulatinamente e que as UF, apesar dos esforços para essa implantação, têm um caminho longo a percorrer.

Há ainda muitas dúvidas relacionadas ao entendimento do ensino híbrido. Tais dúvidas ultrapassam os limites das informações apresentadas na portaria n. ${ }^{\circ}$ 4.059/2004 e apontam para problemáticas que necessitam ser investigadas para, assim, desmitificar-se e se facilitar a compreensão de como o b-learning deve ser implantado pelas IES. Entre essas os dados desta pesquisa podem apontar: o percentual de 20\% de ensino híbrido estabelecido pela portaria n. ${ }^{\circ}$ 4.059/2004 restringe a oferta e implantação do hibridismo nas IES? A falta de informação sobre como adequar o ensino híbrido no PPC (como inscrever e até mesmo como atender metodologicamente o hibridismo no projeto pedagógico do curso) limita o conteúdo das regulamentações institucionalizadas pelas IES ao texto da portaria n. 4.059/2004? A falta de compreensão da conceituação de "ensino híbrido" dificulta a interpretação da portaria n. ${ }^{\circ}$ 4.059/2004 e, consequentemente, a implantação e oferta da semipresencialidade? As Instituições de Ensino Superior oferecem infraestrutura tecnológica necessária para a implantação e oferta do ensino híbrido em seus cursos de graduação presenciais? A falta de capacitação docente para o uso das TIC e sua apropriação dificulta a oferta do ensino híbrido? 
Enquanto, o ensino de graduação nas modalidades presencial e a distância amparam-se em diversas regulamentações, a regulamentação do ensino híbrido ainda se encontra pautada apenas pela portaria n. ${ }^{\circ}$ 4.059/2004. Daí a necessidade de as universidades regulamentarem suas práticas semipresenciais, regulamentação que, no entanto, só será possível após revisão da referida portaria.

Portanto, foi validada a hipótese deste estudo exploratório descritivo, de que a ausência de um detalhamento da oferta de ensino híbrido por meio da portaria n. ${ }^{\circ} 4.059 / 2004$ tem ocasionado diferentes interpretações, dificultando sua implantação.

A implementação do blended learning deve ser precedida de intenso planejamento pelas IES. Assim, o ensino híbrido é configurado como uma combinação metodológica que impacta a ação do professor em situações de ensino, a ação dos estudantes em situações de aprendizagem e, também, a ação dos gestores educacionais, que deverão escolher o modelo de ensino híbrido que melhor se adeque às necessidades de sua instituição.

A regulamentação vigente no Brasil a respeito da semipresencialidade ainda não tornou clara a maneira como as IES deverão implementar o ensino híbrido no currículo de seus cursos.

As IES possuem autonomia para decidir de que forma irão implantar essa modalidade. Regulamentações internas devem ser elaboradas pelas IES para que estas possam implementar o ensino semipresencial. Nesse sentido, cabe salientar que as experiências nas instituições com essa modalidade são basilares para a formulação de regulamentos, os quais passam a existir conforme a necessidade de cada IES. A prática, muitas vezes, antecede as leis e lhes serve de referencial.

Percebeu-se que a maior deficiência da regulamentação do ensino híbrido no Brasil é a falta de informações sobre a oferta do ensino, fazendo com que, muitas vezes, esta possa ocorrer de forma equivocada.

Com base nas reflexões anteriores, pode-se afirmar que o ensino híbrido, autorizado no Brasil pela portaria $n^{\circ} 4.059 / 2004$, já faz parte do contexto da educação contemporânea e, dessa forma, tornam-se necessários esforços relacionados ao entendimento da oferta desse ensino, bem como políticas de gestão que venham a esclarecer essa modalidade. 


\section{REFERÊNCIAS}

BELLONI, M. L. Educação a distância. Campinas: Autores Associados, 2012.

BRASIL. Ministério da Educação. Portaria $n^{\circ} 4.059$ de 10 de dezembro de 2004. Disponível em: <http://www.esab.edu.br/arquivos/pdf/por_2004_4059_ MEC_pdf.>. Acessado em: 06/05/2014.

CHIZZOTTI, A. Pesquisa qualitativa em ciências humanas e sociais. Petrópolis: Vozes, 2008.

COGRAD. Colégio de Pró-Reitores de Graduação das IFES. Propostas do COGRAD para a Educação a Distância nas Instituições Federais de Ensino Superior. 2015. Disponível em: < http://www.andifes.org.br >. Acessado em $13 / 12 / 2015$.

COSTA, H.; ROZZETT, K.; CARVALHO, S.; ODELIUS, C. Hibridização do ensino superior: avaliação de uma iniciativa na disciplina Introdução à Administração (Universidade de Brasília). Novas Tecnologias e Educação. v. 10, no 3, 2012. Disponível em: <www.seer.ufrgs/renote/article/view/36388>. Acessado em 16/07/2015.

GIL, A. C. Como elaborar projetos de Pesquisa. 5a ed. São Paulo: Atlas, 2010.

HORN, M. B.; STAKER, H. Blended: usando a inovação disruptiva para aprimorar a educação. Trad. Maria Cristina Gularte Monteiro. Porto Alegre: Penso, 2015.

LÜDKE, M.; ANDRÉ, M.. Pesquisa em Educação: abordagens qualitativas. São Paulo: EPU, 1986.

MARTINS, H. H. T. de S. Metodologia qualitativa de pesquisa. Educ. Pesquisa. São Paulo, v. 30, n. 2, p. 289-300, ago. 2004. Disponível em: <http://www.scielo. $\mathrm{br} / \mathrm{scielo} \operatorname{lng}=$ en\&nrm=iso $>$. Acessado em: 12/10/2015.

MONTEIRO, A.; MOREIRA, J. A. O b-learning no ensino superior: reflexões em torno de práticas. Cadernos de Pedagogia no Ensino Superior. $n^{\circ}$ 20, p. 23-36, 2012. Disponível em: < https://repositorio-aberto.up.pt/ bitstream/10216/70504/2/87923.pdf > . Acessado em 16/07/2015. 
MORAN, J. M. Propostas de mudança nos cursos presenciais com a educação on-line. In: CONGRESSO INTERNACIONAL DE EDUCAÇÃO A DISTÂNCIA. 2004. Disponível em: <http://www.eca.usp.br/prof/moran/ site/textos/educacao_online/propostas.pdf > . Acessado em 22/07/2014.

; Educação Híbrida: um conceito-chave para a educação hoje. In: BACICH, L.; TANZI NETO, A.; TREVISANI, F. de M. (Org.). Ensino Híbrido: personalização e tecnologia na educação. Porto Alegre: Penso, p. 27-45, 2015.

; ARAÚJO FILHO, M.; SIDERICOUDES, O. A ampliação dos vinte por cento a distância: estudo de caso da Faculdade Sumaré-SP. 2005. Disponível em: <http://www.abed.org.br/congresso2005/por/pdf/172tcc3. pdf $>$.

MOREIRA, J. A.; MONTEIRO, A. O trabalho pedagógico em cenários presenciais e virtuais no ensino superior. Educação, Formação e Tecnologias. v. 3, n ${ }^{\circ}$ 2, p. 82-94, 2010. Disponível em: <http://eft.educom.pt/index.php/eft/ article/viewFile/173/117>. Acessado em 17/07/2015.

OLIVEIRA, R.G.M. Aprendizagem significativa, engenharia didática e sequência fedathi: o ensino de física na escola pública.136p. 2007. (Monografia de Especialização em Ensino e Prática de Física) - Universidade Federal do Ceará, Fortaleza, 2007.

PRETI, O. Educação a Distância: fundamentos e políticas. Cuiabá: EdUFMT, 2009.

PETTER, R. C. A gestão participativa e democrática na EaD e a viabilização dos colegiados - algumas possibilidades. In: PRETTI, O. (org.) Educação a Distância: processos de gestão. Cuiabá: EdUFMT, p. 103-124, 2010.

PORVIR. Ensino Híbrido ou Blended Learning. 2013. Disponível em: $<$ http://porvir.org/ensino-hibrido-ou-blended-learning/ >. Acessado em: $29 / 07 / 2015$.

QUEVEDO, A. O ensino semipresencial do ponto de vista do aluno. Revista e-curriculum. São Paulo. v. 7, no 1, p. 1-21, abril/2011. Disponível em: <http:// revistas.pucspp.br/index.php/curriculum>. Acessado em 17/07/2015. 
RUMBLE, G. A tecnologia da Educação a distância em cenários do terceiro mundo. In: PRETTTI, Oreste (Org.). Educação a Distância: construindo significados. Brasília: Plano, p. 43-61, 2000.

TORI, R. Cursos híbridos ou blended learning. In: LITTO, F.; FORMIGA, M. Educação a distância: o estado da arte. São Paulo: Pearson Educacional do Brasil, p.121-128, 2009

ZANOTTO, M. A. do C.; BIANCHI, P. C. F.; SILVA, A. P. R. da; REALI, A. M. de M. Hibridização do ensino em uma IES: delineamento de ações pedagógicas para adoção de $20 \%$ a distância em cursos de graduação presenciais. In: SIMPÓSIO INTERNACIONAL DE EDUCAÇÃO A DISTÂNCIA. 1. Anais. 2014. Disponível em: <http://www.sied-enped2014.ead. ufscar.br/ojs/index.php/2014/article/view/742>. Acessado em: 17/07/2015.

MICHELE REJANE COURA DA SILVA é graduada em Administração com formação em Empreendedorismo pela Universidade do Estado de Mato Grosso (2007). Mestre em Educação pela UFMT. Possui diploma de Especialização (Pós-Graduação MBA em Gestão Executiva de Negócios pela Universidade de Cuiabá/UNIC). Professora do Ensino Básico, Técnico e Tecnológico do Instituto Federal de Educação, Ciência e Tecnologia de Mato Grosso - Campus Campo Novo do Parecis. Membro do Grupo de Pesquisa: Laboratório de Estudos sobre Tecnologia da Informação e Comunicação na Educação (LêTece). E-mail:michele.silva@cnp.ifmt.edu.br

CRISTIANO MACIEL é Bacharel em Informática pela Universidade Regional do Noroeste do Estado do Rio Grande do Sul (1995), especializado em Avaliação Educacional pela Universidade Federal do Mato Grosso (1998), Mestre em Ciências da Computação pela Universidade Federal de Santa Catarina (1997) e Doutor em Ciência da Computação pela Universidade Federal Fluminense (UFF), com estágio na Universidade de Coimbra, em Portugal (2008). Atualmente é Professor Associado I do Instituto de Computação da Universidade Federal de Mato Grosso (UFMT), professor do Programa de PósGraduação em Educação, pesquisador do Laboratório de Ambientes Virtuais Interativos (LAVI) e Laboratório de Estudos sobre Tecnologias da Informação e Comunicação na Educação (LeTECE); e Diretor Geral da Fundação de Apoio e Desenvolvimento da UFMT (Fundação Uniselva). É Secretário da Regional Mato Grosso da Sociedade Brasileira de Computação (SBC) e Coordenador do Programa Meninas Digitais. E-mail: crismac@gmail.com 
KÁTIA MOROSOV ALONSO possui Graduação em Pedagogia pela Universidade Federal de Mato Grosso (1985), Mestrado em Educação pela Universidade Federal de Mato Grosso (1992) e Doutorado em Educação pela Universidade Estadual de Campinas (2005). Atualmente é professora associada da Universidade Federal de Mato Grosso. Docente do Programa de Pós-Graduação em Educação - PPGE - do Instituto de Educação da UFMT. Líder do Grupo de Pesquisa Laboratório de Estudos Sobre Tecnologias da Informação e Comunicação na Educação - LêTECE. Tem experiência na área de Educação, com ênfase em Educação a Distância. E-mail: katia@ufmt.br

Recebido em julbo de 2016 Aprovado em setembro de 2016 